\title{
Extreme In Situ Mechanics of Bond Coatings and Ni-based Superalloys Using an Advanced SEM Nanomechanical Instrument
}

\author{
Sanjit Bhowmick ${ }^{1}$ and Eric Hintsala ${ }^{2}$ \\ ${ }^{1}$ Bruker, Plymouth, Minnesota, United States, ${ }^{2}$ Bruker Nano Surfaces, Eden Prairie, Minnesota, United \\ States
}

High-strength structural materials such as Ni-based superalloys and diffusion bond coats are widely used in challenging environments and with exposure to mechanical fatigue, particle impact, and erosion at elevated temperatures. Pt-aluminide (PtAl) bond coats are an integral part of thermal barrier coating (TBC) systems operating in the hot sections of gas turbine engines. Platinum in the bond coat provides good adhesion of the TBC to the superalloy substrate and improves its oxidation resistance [1-3]. PtAl bond coats exhibit a three-layered microstructure: (a) an outer layer containing intermetallic $\mathrm{PtAl} 2$ and fine $\mathrm{Cr}$ rich precipitates, (b) an intermediate layer containing $\mathrm{B} 2-(\mathrm{Ni}, \mathrm{Pt}) \mathrm{Al}$, and (c) an inner layer, which is an interdiffusion zone containing coarse $\mathrm{Cr}$-rich precipitates in a $\mathrm{B} 2-\mathrm{NiAl}$ matrix.

This study focuses on understanding deformation mechanisms at elevated temperature and the variation in mechanical properties as a function of temperature in these thermal bond coatings. An advanced in situ SEM nanomechanical instrument, a next generation prototype PicoIndenter (Bruker, Minneapolis, USA) with an integrated $1000^{\circ} \mathrm{C}$ high-temperature stage and active $1000^{\circ} \mathrm{C}$ tip heating was used to conduct uniaxial compression of micropillar samples. Besides providing live high-resolution imaging, it's beneficial to perform these tests in the SEM as the high vacuum environment limits the oxidation of the sample. This is especially important at high temperatures and enables the measurement of the true mechanical properties of the bond coating and superalloy. Water circulation through cooling blocks at the sample heater and transducer minimizes thermal drift of the system.

Micropillars of dimensions $8 \mu \mathrm{m} \times 8 \mu \mathrm{m}$ in cross-section and $25 \mu \mathrm{m}$ in height were prepared from the outer layer of PtNiAl coating and Ni-base superalloy region by focused ion beam (FIB) machining. Insitu quasistatic uniaxial compression experiments were conducted with a $20 \mu \mathrm{m}$ flat punch diamond probe. Using the displacement-controlled feedback mode of the system, the pillars were compressed to 5-12\% strain at a strain rate of $10^{-3} \mathrm{~s}^{-1}$. Compression tests were conducted at room temperature (RT) as well as several elevated temperatures up to $1000^{\circ} \mathrm{C}$.

The microstructure of the pillar surface before and after uniaxial compression of bond coating the and superalloy are shown in Fig. 1. Fig. 2 displays stress-strain curves which are calculated from loaddisplacement data. The stress-strain curves of the bond coating indicate that at room temperature substantial strain hardening after yielding is possible, but is very limited at higher temperatures. This could be caused by a switch in plasticity mechanism to grain boundary sliding at higher temperature, which was observed on the surface of the bond coating pillars. The elastic modulus of the bond coating remains nearly constant up to $900^{\circ} \mathrm{C}$, whereas yield stress of the coating decreases to $\sim 50 \%$. With regards to failure, Transgranular fracture appears on the pillar surface at room temperature whereas intergranular fracture dominates deformation at higher temperature.

Acknowledgement: SB acknowledges collaboration support of Prof. Vikram Jayaram (Indian institute of Science) and Prof. Nagamani Jaya Balila (Indian Institute of Bombay) on Pt-aluminde bond coating. 

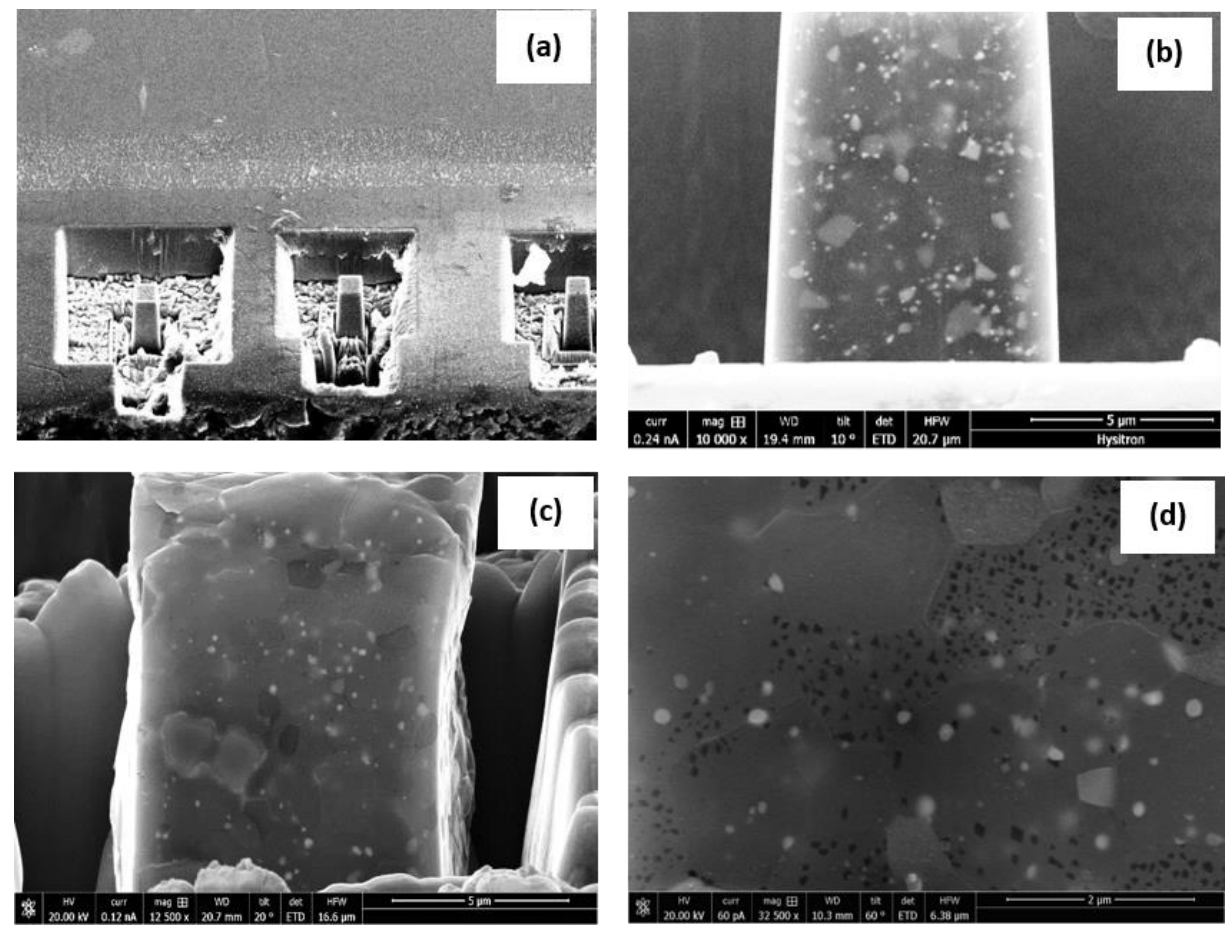

Figure 1. Morphology of the pillars before ( $a$ and b) and after (c and d) compression. (b): Large precipitates of PtAl2 and fine precipitates of $\mathrm{Cr}$ and $\mathrm{W}$ rich are visible on the pillar surface. (c and d): grain boundary sliding can be observed on the pillar surface at $700 \mathrm{oC}$.

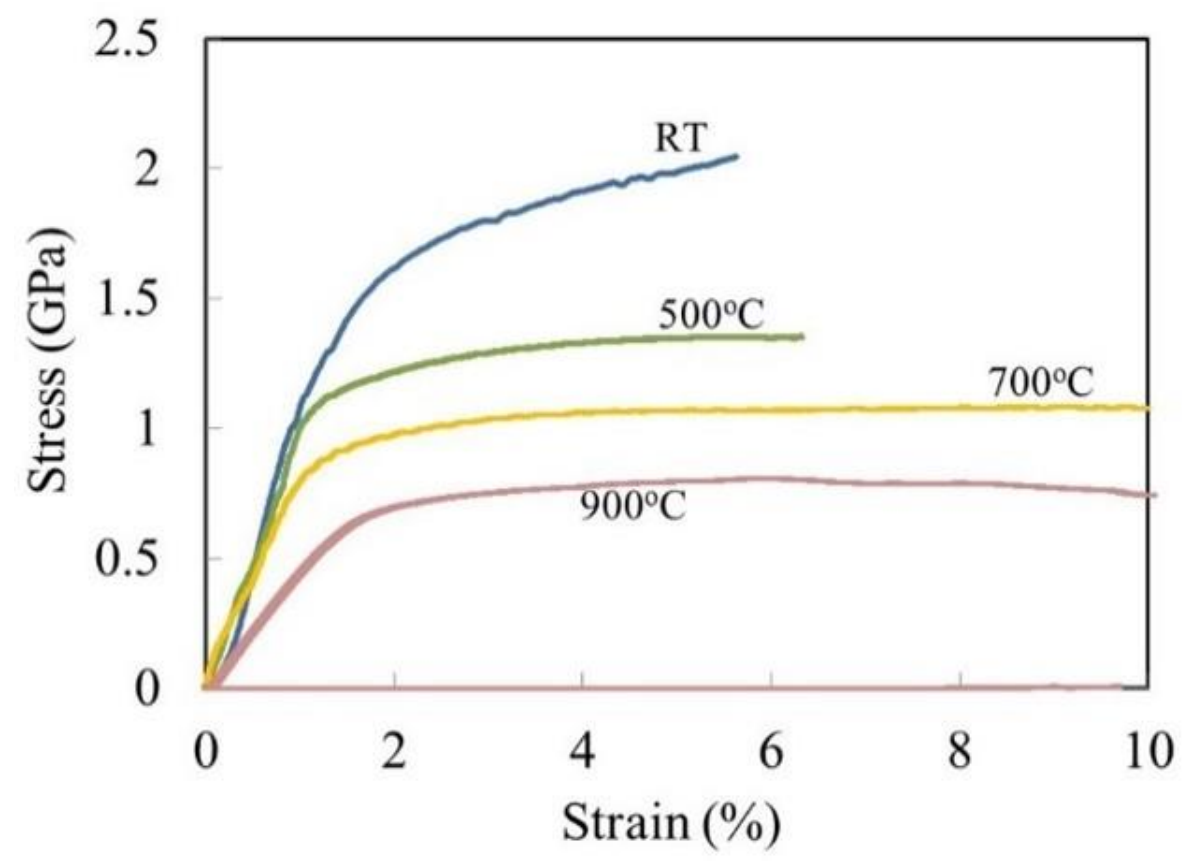

Figure 2. Stress-strain curves of bond coating at room temperature, $500 \mathrm{oC}, 700 \mathrm{oC}$ and $900 \mathrm{oC}$.

\section{References}

1. B. Jaya, S. Bhowmick, S. Asif, V. Jayaram, J. Mater. Res. 30 (2015) 3343.

2. B. Jaya, S. Bhowmick, S. Asif, O. Warren, V. Jayaram, Phil. Mag., 95 (2015) 1946.

3. M. D. Alam, S. V. Kamat, V. Jayaram and D. K. Das, Acta Mat., 67 (2014) 278. 